\title{
The Public Health Campaign: A Literature Review from the Point of Use of Media and Communication in Malaysia
}

\author{
Raja Ismail Shaleh \\ University of North Malaysia, Malaysia \\ Email: raja.ismail09@gmail.com
}

\begin{abstract}
This research describes the historical series of the occurrence of the Balkan Wars and the implications thereof for Muslim life there. This study took three main problems, namely (1) the causes of the Balkan Wars, (2) the chronology of the Balkan wars, and (3) What are the implications of the Balkan wars on the socio-political life of Islam in Southeast Europe. The research method used in this thesis is the historical research method. 4 stages, namely (1) Heuristics, (2) Source/Verification Criticism, (3) Interpretation and (4) Historiography. There are two approaches used in this study, namely the political and sociological approaches. While the theory I use in this research is theory. conflict and social change theory. The results of the research that the authors obtained are: chronologically, the Balkan war was preceded by the problem of Macedonia which in the end was used as an excuse to legitimize the war. Basically, the main cause of this Balkan war was due to the ambition and personal grudge between the respective rulers of the Balkan countries and the Ottoman Empire. It was also driven by the decline of the sultanate, Russian domination, the Turkish-Italian war (1911-1912), the idea of nationalism, propaganda, the formation of the Balkan alliance and the failure of diplomacy. The outbreak of the Balkan war not only resulted in geo-political changes but also was a humanitarian catastrophe for Muslims in the Balkans who at that time had to accept the fact that their situation was no longer the same as when it was led by Muslims because authority had shifted to non-Muslims.
\end{abstract}

Keywords: Media, Communications, Campaigns, Public Health, Malaysia.

\section{A. INTRODUCTION}

Mass media is a technology channel used to spread the message with the aim of attracting a large audience. The disclosure of the message made can at least gain support (Potter, 2011). There are various types of media that exist today including print media such as newspapers and magazines; electronic media such as the internet; social media such as Facebook and Twitter; and online applications such as WhatsApp, WeChat and Telegram as well as many other media dumps that are emerging (Samad, 2014). The media plays an important role in providing information to the public about what is happening in the world, especially in aspects where the audience itself does not have the knowledge or experience of such a thing (Happer \& Philo, 2013). The role of the media does not stop there, it can even be used as a useful medium in the success of a campaign (Junus, 2013).

Campaign is defined by Abdullah (2002) as one of the widely used communication methods for the purpose of reaching the target audience through persuasion strategies. The potential of a media campaign lies in its ability to spread a concise message and focus on a large audience from time to time and the same 
time using low cost (European Monitoring Center for Drugs and Drug Addiction, 2013). The continuous use of media campaigns by some parties is carried out on the basis that this medium is able to reach a large audience so effectively, even though only a few percent of the target audience will be influenced by the message delivered (Atkin, 2009).

A study conducted by Wakefield, Loken, and Hornik (2010) found that media and communication campaigns have been used over the past decade in an effort to influence public health behavior. In this regard, the media has been used in all layers of campaigns conducted in the country including in health communication campaigns. However, the problem that exists is the study of the context and use of media and communication as a preventive intervention on public health awareness campaigns in Malaysia referred to is still limited and requires more research.

Referring to this problem, the purpose of this literature review is to review the use of media and communication in public health awareness campaigns in Malaysia. This review of the literature review is referred to as very important to be implemented so that the combination of existing literature can be used as a useful scientific reference material for future studies in the scope of health communication. The results of this study will be a great and good contribution in further enriching knowledge in the field of health communication. In addition, this study can also indirectly provide encouragement to local researchers to conduct more research studies regarding the use of media and communication in public health awareness campaigns in the country. In fact, this study is proof that the use of media and communication actually plays an important role and is very helpful in becoming a medium of dissemination of public health information, in addition to the key to increasing public awareness of health issues and threats in the country.

\section{B. METHODE}

This research method uses a mixed method research synthesis approach. This approach is a systematic review method in which existing research data will be studied, evaluated and formulated in an orderly manner (Heyvaert et al., 2013). Through the use of this method, all research data are obtained from qualitative, quantitative and mixed manuscripts (Sandelowski et al., 2012). Based on the integration of the findings of the diversity of literature related to the field studied, then the problems of the study raised can be answered (Gough, 2015). This systematic review of the literature also allows for an increase in understanding of the scope of the field focused on the study conducted (Harden, 2010).

Through the use of this mixed method research synthesis approach, then databases such as ScienceDirect, Scopus and Google Scholar are accessed for sample search, namely the manuscript of the journal related to this study. Keywords such as "media and communication" and "public health" were used to search the journal manuscripts published from 2010 to 2015. A total of 80 journal manuscripts were found, only 28 manuscripts were selected. The determination in the selection of samples that are all these manuscripts is based on the suitability of the scope of the 
study that is the use of media and communication in issues under the field of health communication in Malaysia. This literature review includes (7) manuscripts on the issue of the dangers of smoking; (4) manuscripts with respect to public health issues; (3) manuscripts on HIV / AIDS issues; (1) manuscripts with respect to the issue of diabetes; (5) manuscripts with respect to the issue of cancer; (2) manuscripts on the issue of dengue; (1) manuscripts with respect to drug issues; (2) manuscripts on the issue of organ donation; (1) manuscripts with respect to breastfeeding issues; (1) manuscripts with respect to the H1N1 issue; as well as (1) manuscripts with respect to the SARS issue. All manuscripts of this journal have been reviewed in the context of the use of media and communication for each theme discussed.

\section{RESULT AND DISCUSSION}

Health communication campaigns are conducted in an effort to provide a healthy behavioral impact among the current population in a country (Randolph, Whitaker, \& Arellano, 2012). This is because sometimes there are members of society who have a high awareness in addition to having knowledge or information on how to live a healthy lifestyle, but do not make it a practice in daily lifestyle (Krishnan \& Rahim, 2014). Thus, the media campaign carried out the role of disseminating information on public health and threats in this issue, as well as persuading community members to accept the proposed behavioral changes (European Monitoring Center for Drugs and Drug Addiction, 2013).

A study conducted by Hassali et al. (2012) found that the mass media has been rated as the best source of information on the promotion of health activities. The majority of respondents stated that the mass media in general as the best source followed by the selection of newspapers and advertising as the second and third best sources. The results of a study conducted by Mohamad, Haniff, Salleh, Ahmad, and Hashim (2015) found that the majority of respondents chose the internet as their source of information on health. The Internet makes accessing information about children's health and nutrition faster and easier. The results of this study also found that the source of information from social media is no exception is also easy to refer to.

In contrast to the findings of a study by Osman and Adzharuddin (2015), campaign advertising posters that have visual and verbal elements were found to be able to impact the emotions of the target audience. For example, feelings of excitement, joy, excitement, boredom, excitement, sadness or fear. Both of these elements are able to make an impact in terms of the physiology and psychology of the target audience. In addition, a study conducted by Krishnan and Rahim (2014) also found that communication factors such as information retrieval actions, health involvement and referrals to act can also bring positive changes among respondents.

The following sections will discuss the use of media and communication in several health issues in Malaysia. Important aspects such as the role, implications 
and effectiveness of media and communication in the delivery of information on public health issues will also be reviewed.

\section{The Dangers of Smoking}

The No Smoking Campaign was launched in 2004 by Tun Abdullah Ahmad Badawi and continues to this day to provide awareness to the community about the dangers of smoking (MyHEALTH Portal Ministry of Health Malaysia, 2016b). However, the number of smokers in the country referred to is still high. The proof, it is estimated that as many as five million adults in the country are smokers aged 15 years and above (Sazale \& Ghapar, 2017).

A study conducted by Zawahir et al. (2013) found that as many as 75.4 percent of adolescents are aware of the display of media messages about antismoking campaigns conducted in the country. A total of 60 percent of respondents involved in the study by Bakar \& Zakaria (2013) stated that anti-smoking advertisements are most often seen by them through television channels, in addition to 90 percent and 73 percent of respondents stated print and radio media as the most medium they often see and hear anti-smoking ads.

The results of a study conducted by Maarof \& Osman (2013) also found that advertising in the No Smoking Campaign has the ability to influence adolescents who smoke to quit smoking. The majority of adolescents involved in the study were able to accept the contents of the campaign and strive to quit smoking after seeing the display of horrible images on cigarette boxes such as oral cancer graphics, heart disease and many more. The findings of this study are supported by the results of the study of Bakar et al. (2013) where most of the respondents involved in the study (70 percent) stated that the images displayed have the ability in giving them awareness to quit smoking.

Moreover, a study conducted by Bakar (2015) found that the combination of elements of fear and emotion in media advertising about the dangers of smoking is a good strategy to use. This strategy is effective in increasing respondents' knowledge of the effects of smoking. Respondents' perceptions, attitudes and behaviors can also be changed from smoking to non-smoking. As many as 70 percent of smokers involved in this study stated that they would think twice about smoking after watching an advertisement that possessed these two elements.

However, a study conducted by Hong et al. (2013) found that the average respondent did not agree that fearful messages are effective in promoting antismoking advertisements. These findings are in line with the results of a study by Bakar et al. (2013) who showed that a total of 60 percent of respondents agreed that messages through pictures of diseases displayed on cigarette boxes did not directly scare them to smoke. However, the element of 'fear' can achieve effectiveness if accompanied by a high impact message. For example, information on how to call Quitline to provide assistance to smokers (Tobacco Free Florida, 2015). The results of the study of Hong et al. (2013) also found that the internet is the most effective medium in promoting anti-smoking advertising. 
A study conducted by Hassan, Yusof, and Hashim (2014) also reported that the No Smoking Campaign became ineffective as a result of innovations that were not acceptable to those who smoked. Smokers who are extremely addicted see the decision to quit smoking as irrational and continue to smoke. This is compounded by the concern to withstand severe addiction to cigarette nicotine. A study conducted by Maarof and Osman (2013) also mentioned that the increase in the number of smokers from year to year seems to give the impression that media and communication strategies have not been effective enough in raising public awareness on this issue.

In addition, Bakar et al. (2013) in their study also discussed the role of communication channels in the process of changing behavior. In this regard, this study refers to the anti-smoking campaigns that are regularly broadcast on various communication channels are able to play an important role in the process of changing children's perceptions and behavior towards cigarettes. However, exposure to poorly acquired anti-smoking campaigns by children results in less information on the dangers of smoking. This also makes it difficult for them to quit smoking. Therefore, the results of this study suggest that if the campaign organizers want to conduct promotion to various segments of the target audience, then techniques and media channels specific to a target audience should be examined. This matter is important to be studied and scrutinized to ensure that the chosen communication channel truly meets the needs, suitability and tastes of the selected target audience for the delivery of the message that has been set. In this way, the message conveyed will be easier for the target audience to accept as a result of research and study on how to deliver the message to them.

\section{HIV/AIDS Issues}

Malaysia has not been able to bear the burden of HIV / AIDS problems since the discovery of its first case in December 1986 (Huddart, 2000). A report released by the Malaysian AIDS Council and the Malaysian AIDS Foundation (2017) shows that the cumulative number of HIV cases in the country during the period from 1986 to 2015 was 108,519 people. The amount was contributed by heterosexuals by 42 percent, homosexual or bisexual by 36 percent, those who inject drugs (users by 17 percent, mothers to children by 4 percent and other means of infection by 1 percent.

A study conducted by Sern \& Zanuddin (2015) showed that 73.3 percent of respondents tend to get information about HIV/AIDS through the press. Information on this issue was also obtained through television media (73.1 percent of respondents) and the internet (72.2 percent of respondents) as the second and third highest media selected. The results of the study concluded that the media has great potential in correcting public misunderstandings and perceptions about HIV/AIDS and people living with HIV/AIDS as well as providing information on government initiatives and efforts to address HIV/AIDS in the community. 
A study conducted by Sern \& Zanuddin (2012a) also concluded that placing news on HIV / AIDS as a priority is one of the methods of media involvement in AIDS education. The findings of the study show that the issue that received the highest coverage in The Star media is about the government's response and community involvement in addressing HIV / AIDS issues. However, The Star media reporting on issues related to HIV / AIDS is still limited as it is based on domestic events, community programs or policy decision-making made by the authorities only. Overall, this study refers to the need for the media to mobilize the public to convert the knowledge of HIV / AIDS that has been instilled by the media into action in the context of acceptance of people living with HIV / AIDS as well as the prevention of health behaviors.

In fact, another study conducted by Sern \& Zanuddin (2012b) refers that current media reports on issues related to HIV/AIDS are still not enough in educating the public on this issue. The study refers to the media as having a major role in influencing public perceptions. Therefore, improvements in the use of media for the delivery of information on this issue should be made to reduce the stigma and negative perception of this issue. This is because the results of the study also found that there are conflicts that occur in media coverage related to the issue of HIV / AIDS. This conflict involves the perception of the article and the title used where the negative elements exist. For example, an article released by Utusan Malaysia entitled "HIV positive jailed and caned" which turned out to show a negative element to people living with HIV / AIDS.

\section{Cancer Issues}

Cancer is the name given to a group of related diseases in which it can be said that all types of cancer occur, some of the body cells begin to divide non-stop and spread into the surrounding tissues (National Cancer Institute, 2015). In Malaysia, cervical cancer is the third cancer with the highest number of cases among women (Manan, 2016). Based on references to statistics released by the Ministry of Health Malaysia, it is found that about 19,000 out of 100,000 people in Malaysia suffer from various types of cancer (Msar, 2016).

A study conducted by Saleh et al. (2012) found that the use of television media and brochures was the highest choice of respondents in obtaining information on cancer issues. The majority of respondents knew the signs of oral cancer through television media (26.1 percent of respondents) followed by brochures (22.0 percent of respondents). The findings of this study are most likely the result of the use of pamphlets by the Ministry of Health Malaysia distributed in government hospitals and clinics in the past few years to educate the public on oral examination. The majority of respondents involved in the study stated that at least one of the signs of oral cancer was obtained from television media. This matter is also referred to by this study that television is a good medium in disseminating information to the public about oral cancer. 
The results of the study of Saleh et al. (2012) this is clearly in line with the findings of a study by San et al. (2015) where a total of 88 percent of respondents (highest percentage) stated that they are most exposed to cervical cancer ads through television media channels. The Internet and pamphlets ranked second and third in the highest percentage of respondents' choice of the media most exposed to cervical cancer ads, with 84.3 percent of respondents and 77.7 percent of respondents respectively. Overall, the findings of this study clearly show that the exposure of cervical cancer ads is high on all respondents who have conducted smear tests in this study. Traditional media referred to still plays an important role along with new media in disseminating information regarding cervical cancer to the public. This is because the level of exposure to cervical cancer ads using this traditional media is still high. Therefore, this study at the end of the discussion refers to that the message sent to the community about cervical cancer should be of good quality and easy for them to access. In the context of the level of trust and validity of information, this study refers to the quality of media coverage can be further enhanced while suggesting that exposure to this issue and legitimate and reliable cervical cancer resource access strategies to the journalists involved can be carried out.

In addition, the findings of the study of Saleh et al. (2012) is also supported by a study conducted by Ghani et al. (2013) where the results show that respondents mostly get information about oral cancer through mass media (35.3 percent of respondents) followed by health campaign (21.4 percent of respondents), doctors and health staff (15.3 percent of respondents), internet (13.2 percent of respondents) and family members or neighbors (12.9 percent of respondents). General awareness of this oral cancer is undeniably present among the respondents, but a deeper awareness is still lacking. Mass media strategies are needed to provide awareness to the public about the symptoms of these symptoms, the risky habits that make up this infection and ways to prevent it.

A study conducted by San et al. (2014) found that the effects of exposure conducted by the mass media make interpersonal communication need to play an important role. This is important in handling individual views on possible health problems. The level of need for information, direct experience, psychological and demographic influences were found to be factors that led to the search for information on cervical cancer. Studies conducted by Akhtari-Zavare, et al. (2011) refer to the use of media in reporting on breast cancer in Malaysia is needed to expose the public to the risk factors for this disease. The results show that family history and age are among the most identified factors to this issue.

\section{Drug Issues}

A report released by the National Anti-Drug Agency (AADK) of the Ministry of Home Affairs shows that the number of registered addicts recorded in the country from 1988 to 2015 was 413,754 people. The state of Penang topped the chart as the state with the highest number of registered addicts at 54,022 people (National 
Anti-Drug Agency of the Ministry of Home Affairs, 2015). The latest statistics released by the Malaysian Crime Prevention Foundation (MCPF) show that it is estimated that almost 1.5 million Malaysians have been involved in drug abuse since the 80s (Abdullah, 2016).

A study conducted by Khir, Sajahan, Johari, and Jaafar (2010) found that the majority of anti-drug campaigns conducted by the AADK were realized by the respondents interviewed. A total of 14.5 percent of respondents said that the AADK website itself as their source knew the information about the anti-drug campaign conducted. Radio is also identified as the best electronic media on behalf of AADK to maximize for the purpose of informing about their activities to the community. The remaining respondents received information on anti-drug campaigns through talks and exhibitions conducted by AADK. The public awareness of the anti-drug campaign conducted by AADK clearly reflects the success in the context of the promotion carried out.

Preliminary studies by Ahmad, et al. (2012) found that media acceptance in anti-drug campaigns in the country is growing. The majority of respondents involved in the study were found to have a moderate level of knowledge and awareness of the dangers of drug abuse through campaigns and communication strategies conducted. The results of the study also show that there are two forms of communication strategies used on average in raising public awareness of the dangers of drug abuse, namely mass media (such as television, radio, newspapers and internet) and outdoor advertising (such as signboards and brochures).

\section{Other Health Issues}

Diabetes is a non-communicable disease as a result of unhealthy lifestyle practices by some communities today (Sulaiman, 2016). It occurs when the body does not produce or use the hormone insulin properly to convert sugar, starch and other foods into energy (Diabetes Community Portal, 2006). As of 2015, a total of 17.5 percent of the people in the country have diabetes. A total of 89 percent of them do not know that they have the disease (Adnan, 2016). This percentage has increased to 17.5 percent in 2015 compared to 11.6 percent in the previous 10 years (Sulaiman, 2016).

A study conducted by $\mathrm{Ju}$ et al. (2010) found that a total of 31.1 percent of respondents have used press and magazine media in obtaining health information in addition to television and radio of 17.6 percent of respondents. However, the level of knowledge about nutrition is in a satisfactory status especially among the uneducated senior citizens and are in a low economic status.

Apart from that, the health issue of dengue fever in this country is still unresolved until today. The proof, the accumulated number of dengue cases that occurred in the country from early January 2016 to 9 July 2016 was reported as many as 59,294 cases by the Ministry of Health Malaysia (Mutalib, 2016). Dengue fever is a disease caused by a viral infection through a bite by an infected aedes aegypti mosquito (MyHEALTH Portal Ministry of Health Malaysia, 2016a). 
A study conducted by Aung et al. (2016) found that the majority of respondents obtained information on dengue issues through various mediums. This medium covers the use of mass media, internet, newspapers, pamphlets, health campaigns, books and the community around them. There is no dominant media in conveying information about dengue to the community. Studies conducted by AlDubai et al. (2013) also refer that awareness about dengue fever is mostly obtained by respondents based on information by mass media sources. Television media recorded the highest percentage of respondents as a source of information. The print media is also not the second highest source of information selected. Radio media as well as talks and seminars are the third highest source of information selected.

In addition, organ donation is also an important health issue to refer to in this country. Organ donation is a process in which the transfer or transplantation of a healthy part of an organ or tissue is done from one individual to another (MedlinePlus, 2016). Organ donation allows an individual who has previously suffered organ or tissue damage to continue living as usual as a result of the transplantation process carried out (Portal 1 CLICK, 2008). However, the rate of organ and tissue donation in this country was referred to as one of the lowest in the world when it recorded 0.6 donations per million population ("The organ donation rate in Malaysia is very low," 2016).

A review of a study conducted by Ahmad, Ibrahim, Mustaffa, and Kee (2011) found that the mass media plays an important role in conveying information to society about organ and tissue donation. In the context of information retrieval, the results of the study showed that as many as 79.2 percent of respondents use the press media to obtain information on organ and tissue donation issues. Television media is the second highest source of information with a record of 75.9 percent of respondents followed by 63.3 percent of respondents using posters and 61.6 percent of respondents using pamphlets. However, if referred to in the context of respondents' focus on the media, the findings of the study are clearly different compared to the percentage of respondents in the context of information retrieval. In this case, the poster media was found to be the most frequently focused through a percentage of 60.4 percent of respondents, followed by the press media of 26.5 percent of respondents and leaflets of 22.4 percent of respondents. Cinema media was referred by 26.1 percent of respondents as a media that was never focused. Furthermore, in the context of information adequacy, the results of the study found that information on organ and tissue donation in the media was referred by 28.6 percent of respondents as still moderately sufficient and needs to be added. Meanwhile, for the level of trust, 43.3 percent of respondents believe the information conveyed through television media, followed by the press media believed by 41.2 percent of respondents as well as radio, internet and books which each recorded the same percentage of confidence level of 40.4 percent of respondents. The findings of this study are clearly in line with the results of a study by Lisa @ Andi, Rahim, and Lyndon (2015). The results of their study found that organ donation campaigns 
conducted by the government and non-governmental organizations were noticed by the majority of respondents involved in the study. In fact, the majority of respondents also stated that organ donation campaign activities are known to them through the medium of television or radio broadcasts, brochures, internet, magazines, newspapers, exhibitions and group discussions.

In addition, the importance of breastfeeding for the nutrition of infants and children has been promoted since the 1970s (Official Portal of the Nutrition Division of the Ministry of Health Malaysia, 2014). In an effort to increase awareness and knowledge of breastfeeding knowledge, various programs have been organized in the country. Among them is the celebration of breastfeeding week worldwide (Tarmudi, 2015).

The findings of Mohamad (2011) study show that the media plays a big role in raising awareness of breastfeeding among the community. However, coverage of breastfeeding issues in the country is still limited. The coverage also focuses on specific media such as parenting magazines compared to the general media. This clearly limits access to storytelling about breastfeeding to certain groups such as parents. This is in stark contrast to the promotion of formula milk in advertising in the media referred to more readily available and accessible to a wider audience. The issue of sensitivity in the culture of this country in terms of breast exposure is a factor leading to the lack of discussion on the issue of breastfeeding in the media. However, this study concludes that this issue can actually still be discussed in the media without displaying the image of the breast itself.

In addition, Malaysia was shocked by the first case of influenza A (H1N1) virus on 15 May 2009 when a student who had just returned from the United States was confirmed positive for the virus (Chong, 2009). Influenza A (H1N1) virus or another name (Swine Flu) is a disease of the respiratory system found in swine herds. The virus has been detected in humans since 1988 globally (Universiti Sains Malaysia Engineering Library, 2016). However, the Ministry of Health Malaysia refers that the situation of H1N1 infection in the country until April 2015 is still under control. Therefore, its declaration as an epidemic in the country referred to still does not need to be implemented ("H1N1 In Malaysia Still Controlled," 2015).

The use of media in providing awareness to the public on the H1N1 issue in the country is referred to as very useful. The proof, the survey on the study conducted by Mahmud \& Siarap (2013) on the issue of H1N1 in the Northeast area of Penang The use of media in providing awareness to the public about the issue of H1N1 in the country is referred to as very useful. The proof, the survey on the study conducted by Mahmud \& Siarap (2013) on the issue of H1N1 in the Northeast area of Penang found that overall the level of knowledge of the residents on the message conveyed through the campaign conducted is at a moderate level. Television media has played an important role in increasing the level of knowledge of the population through the exposure of H1N1 campaign messages. The attitude of the residents in the Northeast area of Penang is also positive towards the message conveyed in this campaign. A total of 342 residents involved in the study believed in the H1N1 
prevention campaign. In fact, they also practice the things conveyed through the message of this campaign. For example, the practice of washing hands every time you touch a contaminated surface.

Other health issues that arise in the country are SARS (Severe Acute Respiratory Syndrome). SARS is a severe acute respiratory disease and can lead to pneumonia has also hit the country (Ministry of Health Malaysia, 2003). The first case of death in Malaysia related to this epidemic was reported by the authorities on 5 April 2003 (Ibrahim, 2013).

A review of a study conducted by Sannusi \& Siarap (2014) found that the Ministry of Health Malaysia $(\mathrm{MOH})$ through the role of public relations has used the National SARS Operations Room in an effort to ensure that the community at the local and international levels always obtain information on this issue. Several mediums have been used such as hotline lines, $\mathrm{MOH}$ websites, publication of printed materials in the dissemination of information on SARS to the public (such as brochures and posters) as well as cooperation with the media through daily reports sent from time to time. The use of these public relations and mass media strategies is referred to to some extent to alleviate public concern about this issue. Overall, the $\mathrm{MOH}$ succeeded in handling this crisis through assistance in raising awareness and education on the issue of SARS to the community. The panic among the community on this issue was also successfully controlled by the $\mathrm{MOH}$ through the efficiency of its public relations.

The findings show that the use of media and communication in the delivery of information about public health is generally effective. Based on a review of all selected literature, television, internet and newspaper media are referred to as the three media that get the highest selection by the community. All three media are effective sources of public health information. A study conducted by Wilson, Grigg, Graham, and Cameron (2005) supports the findings of this study. The results of the study found that advertising in the television media in the smoking cessation campaign in New Zealand was effective. Expenditure made on the public health sector through television advertising is referred to as a good study.

Media and communication are also useful educational tools. Public awareness on referenced public health issues can be enhanced through informative media messages. The increase in the level of public knowledge on health issues such as the symptoms of a disease and the risk factors for a particular disease is an encouraging development. Negative attitudes and behaviors of public health can also be changed to positive. In fact, there are health messages conveyed by the media are also practiced among members of the community. These findings are clearly in line with the study conducted by Boles et al. (2014). The results of the study showed that almost 80 percent of respondents agreed that the media campaign successfully gave them awareness of the disadvantages of excessive use of sugar in beverages that can lead to health problems. In fact, the effects of this media advertising campaign have also succeeded in persuading them to reduce the use of soda and sweet drinks that are always given to their children at home. 
In fact, the large role of media and communication allows it to influence the perception of society. Misunderstandings and negative perceptions that exist in society about a health issue can be corrected using the media. For example, the stigma and discrimination against people living with HIV / AIDS that still exists in some communities can be eradicated little by little. The findings of this study are supported by the results of studies by Bekalu et al. (2014). The results of the study found that excessive media exposure can lead to a reduction in stigma against HIV / AIDS.

The presentation of public health information by the media can also have an impact on the physiology and psychology of society. The combination of elements such as visual, verbal, fear and emotion makes media messages more impactful. The findings of this study are in line with the study conducted by Witte and Allen (2000). The results of the study found that the use of strong elements of fear along with messages that have a high effectiveness can produce significant behavioral changes. The results of the study clearly show that media messages become more impactful when elements such as fear are included

However, some health issues that have yet to find an end are indications that media strategies need to be improved further. The media message with fear alone is not enough. The findings of this study are in line with the study conducted by Kamal et al. (2013). The results of the study found that there are two findings of the situation obtained, namely in the context of short and long term. First, the visual communication displayed on the cigarette box does indeed have the ability to touch the emotions of the audience through feelings of fear among the audience as a result of the message conveyed. However, this situation is only temporary. This is because the display of this visual communication message in the long run eventually makes the matter as something normal for them and at the same time makes the message conveyed through visual communication is no longer ignored.

\section{CONCLUSION}

Overall, based on this literature review, it is clear that the role of media and communication is not limited to just a medium of information delivery, but can even be used in addressing public health issues that occur in a country. The advantage of this medium, one of which is interactive, has indirectly helped to facilitate the process of forming public opinion on an issue, including on public health issues. The strategy of using media and communication applied through a combination of various elements such as persuasion, fear, emotion and others turned out to be a good variation in an effort to make a message conveyed more interesting and high impact. Through the efforts and diversity of ways of conveying the message carried out, it is a matter that it is not impossible that public awareness of an issue, especially on public health issues can be improved from time to time.

In conclusion, media and communication can be used as an intervention to form and raise awareness on public health issues among the people in this country. In an effort to reduce public health problems, especially about the dangers of drug 
abuse and its side effects, the use of appropriate media and communication channels is seen to be a very good and effective helper. Increased awareness of public health among the community is referred to be able to lead to changes in society's attitudes and behaviors. Public health problems that occur in this country are also referred to be reduced if the media and communication interventions are successful in the context of knowledge education delivered from time to time. This matter is referred to be realized if innovation on the use of existing media and communication is enhanced and intensified. Future studies should examine the best alternatives in improving the usability of media and communication to be more impactful in the delivery of information especially on public health issues in the country.

\section{REFERENCES}

1. Abdullah, M. Y. H. (2002). Merancang Kempen Komunikasi Berasaskan Penilaian Formatif. Jurnal Komunikasi, 17, 43-56.

2. Barker, G. (2007). Adolescents, social support and help-seeking behaviour: an international literature review and programme consultation with recommendations for action.

3. Corcoran, N. (Ed.). (2013). Communicating health: strategies for health promotion. Sage.

4. Dutta-Bergman, M. J. (2005). Theory and practice in health communication campaigns: A critical interrogation. Health communication, 18(2), 103-122.

5. Eades, C. E., Ferguson, J. S., \& O'Carroll, R. E. (2011). Public health in community pharmacy: a systematic review of pharmacist and consumer views. BMC public health, 11(1), 582.

6. Farooqui, M., Hassali, M. A., Knight, A., Shafie, A. A., Farooqui, M. A., Saleem, F., ... \& Aljadhey, H. (2013). A qualitative exploration of Malaysian cancer patients' perceptions of cancer screening. BMC public health, 13(1), 48.

7. Grilli, R., Ramsay, C., \& Minozzi, S. (2002). Mass media interventions: effects on health services utilisation. Cochrane database of systematic reviews, (1).

8. Hawn, C. (2009). Take two aspirin and tweet me in the morning: how Twitter, Facebook, and other social media are reshaping health care. Health affairs, 28(2), 361-368.

9. Lin, L., Jung, M., McCloud, R. F., \& Viswanath, K. (2014). Media use and communication inequalities in a public health emergency: a case study of 20092010 pandemic influenza A virus subtype H1N1. Public health reports, 129(6_suppl4), 49-60.

10. Lin, L., Savoia, E., Agboola, F., \& Viswanath, K. (2014). What have we learned about communication inequalities during the H1N1 pandemic: a systematic review of the literature. BMC Public Health, 14(1), 484.

11. Ling, J. C., Franklin, B. A., Lindsteadt, J. F., \& Gearon, S. A. (1992). Social marketing: its place in public health. Annual review of public health, 13(1), 341362. 
12. McAfee, T., Davis, K. C., Alexander Jr, R. L., Pechacek, T. F., \& Bunnell, R. (2013). Effect of the first federally funded US antismoking national media campaign. The Lancet, 382(9909), 2003-2011.

13. Parveen, F., Jaafar, N. I., \& Ainin, S. (2015). Social media usage and organizational performance: Reflections of Malaysian social media managers. Telematics and informatics, 32(1), 67-78.

14. Schliemann, D., Su, T. T., Paramasivam, D., Somasundaram, S., Ibrahim Tamin, N. S. B., Dahlui, M., ... \& Donnelly, M. (2019). The systematic cultural adaptation of a UK public health cancer awareness raising programme for Malaysia: the Be Cancer Alert Campaign. Translational behavioral medicine, 9(6), 1087-1099.

15. Ukoha, C., \& Stranieri, A. (2019). Criteria to measure social media value in health care settings: narrative literature review. Journal of Medical Internet Research, 21(12), e14684. 